(C) 2019 Elsevier B.V. This manuscript version is made available under the $\mathrm{CC}-\mathrm{BY}-\mathrm{NC}-\mathrm{ND} 4.0$

\title{
On Staggered Prices and Optimal Inflation ${ }^{\underline{2}}$
}

\author{
Asier Aguilera-Bravo ${ }^{\mathrm{a}}$, Miguel Casares ${ }^{\mathrm{b}, \mathrm{c}}$ \\ ${ }^{a}$ Universidad de Navarra \\ ${ }^{b}$ Universidad Pública de Navarra \\ ${ }^{c} I N A R B E$
}

October 2, 2019

\begin{abstract}
This paper computes the steady-state optimal rate of inflation in a model with monopolistic competition under two different sticky-price specifications, Calvo (1983) and Taylor (1980). The optimal rate of inflation is positive and almost identical to the ratio between the rate of discount and the Dixit-Stiglitz elasticity.
\end{abstract}

Keywords: Monopolistic Competition, Sticky Prices, Optimal Inflation

JEL classification: E12, E31, E52

\section{INTRODUCTION}

The objective of this paper is to calculate the optimal steady-state rate of inflation in economies with monopolistic competition and sticky prices. To this purpose, two standard types of slow priceadjustment specifications are introduced in a deterministic framework: Calvo (1983) partial adjustment based on fixed probabilities, and Taylor (1980) staggered price contracts.

We calculate the inflation rate that maximizes welfare in steady state. Our optimality analysis is based on the steady-state link between inflation and the mark-up of prices over the marginal cost of production. This mark-up is recognized as a source of economic inefficiency that stems from monopolistic competition. ${ }^{1}$ Therefore, the rate of inflation that maximizes the utility of the representative household is also the one that minimizes the mark-up in steady state.

Remarkably, we find that the optimal rate of inflation in steady state is approximately equal to the ratio between the rate of discount and the Dixit-Stiglitz elasticity. This result is robust for different schemes and degrees of price stickiness. In addition, we compute and compare the welfare cost of steady-state inflation for Calvo and Taylor specifications, and find different welfare losses.

\footnotetext{
${ }^{\sqrt{4}}$ We are very grateful to Ramon Marimon, Dirk Krueger and Omar Rachedi for their helpful comments and feedback on a previous version of this article. Asier Aguilera-Bravo gratefully acknowledges financial support from Fundación Banco Sabadell, Fundación Bancaria Caja Navarra and Universidad Pública de Navarra. Miguel Casares would like to acknowledge financial support from the Spanish Ministerio de Ciencia, Innovación y Universidades (research project PGC2018-093542-B-100). Corresponding author: Miguel Casares, Departamento de Economía, Universidad Pública de Navarra, 31006, Pamplona (SPAIN). E-mail: mcasares@unavarra.es

${ }^{1}$ See King and Wolman $(1996,1999)$ and Khan et al. (2003).
} 


\section{MONOPOLISTIC COMPETITION AND STICKY PRICES IN STEADY STATE}

The production sector of the economy has a continuum of monopolistically competitive firms as in Dixit and Stiglitz (1977), each of them producing a differentiated good in a deterministic environment. Thus, firm $i$ sets the price $P_{t}(i)$ in period $t$, and the amount of output that will sell, $y_{t}(i)$, is given by the Dixit-Stiglitz demand function

$$
y_{t}(i)=\left(\frac{P_{t}(i)}{P_{t}}\right)^{-\theta} y_{t}
$$

where $\theta>1$ is the elasticity of substitution between differentiated goods, $P_{t}$ is the aggregate price level, and $y_{t}$ is aggregate output.

Production technology follows a Cobb-Douglas function that combines capital and labor, with $0<\alpha<1$ as the output elasticity with respect to capital. Both capital and labor are obtained in perfectly competitive markets, and the optimizing behavior of firms leads to this expression for the real marginal cost

$$
m c_{t}=\left(\frac{w_{t}}{1-\alpha}\right)^{1-\alpha}\left(\frac{r_{t}^{k}}{\alpha}\right)^{\alpha}
$$

where $w_{t}$ is the real wage and $r_{t}^{k}$ is the real cost of renting capital.

\subsection{Optimal Price Under Calvo Scheme}

Following Calvo (1983), in every period there is a constant probability $\eta$ that firms will not be able to change prices. Let $\beta=(1+\rho)^{-1}$ be the deterministic discount factor, where $\rho>0$ is the discount rate. If firm $i$ is able to set the price in period $t$, it solves

$$
\max _{P_{t}(i)} \sum_{j=0}^{\infty} \beta^{j} \eta^{j}\left\{\left(\frac{P_{t}(i)}{P_{t+j}}\right)^{1-\theta} y_{t+j}-m c_{t+j}\left(\frac{P_{t}(i)}{P_{t+j}}\right)^{-\theta} y_{t+j}\right\}
$$

which leads to the following optimal price in a steady state with a constant trend inflation rate, $\pi$, and a constant real marginal cost, $m c$

$$
P_{t}(i)=\frac{\theta}{\theta-1}\left[\frac{1-\beta \eta(1+\pi)^{\theta-1}}{1-\beta \eta(1+\pi)^{\theta}}\right] P_{t} m c
$$

\subsection{Optimal Price Under Taylor Scheme}

Alternatively, let us assume that firms can adjust prices with a constant frequency as proposed by Taylor (1980). In particular, firms decide new prices every $J$ periods, remaining unchanged meanwhile. If firm $i$ resets the price in period $t$, the optimization problem is

$$
\max _{P_{t}(i)} \sum_{j=0}^{J-1} \beta^{j}\left\{\left(\frac{P_{t}(i)}{P_{t+j}}\right)^{1-\theta} y_{t+j}-m c_{t+j}\left(\frac{P_{t}(i)}{P_{t+j}}\right)^{-\theta} y_{t+j}\right\}
$$


The optimal price in a steady state with constant inflation is

$$
P_{t}(i)=\frac{\theta}{\theta-1}\left[\frac{1-\beta^{J}(1+\pi)^{J \theta}}{1-\beta^{J}(1+\pi)^{J(\theta-1)}} \frac{1-\beta(1+\pi)^{\theta-1}}{1-\beta(1+\pi)^{\theta}}\right] P_{t} m c
$$

\section{RESULTS}

\subsection{Inflation and Mark-ups}

Firm market power results in a mark-up of prices over marginal costs, which creates a wedge between the marginal productivities of inputs and their corresponding marginal payments. Consequently, the equilibrium levels of capital and labor turn lower with a higher mark-up. This distortion stemming from monopolistic competition motivates the search for economic policies to reduce the mark-up and improve the aggregate economic activity. Specifically, this paper looks for the inflation rate that maximizes welfare in a deterministic (long-run) framework, which is the one that minimizes the mark-up in steady state.

Hence, we derive the steady-state mark-up depending on inflation for the two alternative stickyprice schemes described in the previous section. By looking at equations (1) and (2), we notice that the optimal price, $P_{t}(i)$, is equal to the product of the firm-level mark-up and the nominal marginal cost, $P_{t} m c$. Comparing (1) and (2), we see that the firm-level mark-up can be decomposed into its common component, $\theta /(\theta-1)$, and a specific component that depends on the price stickiness parameter $(\eta$ and $J$, respectively, in the Calvo and Taylor specifications).

If we multiply both sides of equations (1) and (2) by $P_{t} / P_{t}(i)$, we find the aggregate price level as a proportion, $\mu_{t}>1$, of the nominal marginal cost: $P_{t}=\mu_{t} P_{t} m c$. Therefore, $\mu_{t}$ is the aggregate mark-up, which under Calvo and Taylor is given, respectively, by

$$
\begin{gathered}
\mu_{t}=\frac{\theta}{\theta-1}\left[\frac{1-\beta \eta(1+\pi)^{\theta-1}}{1-\beta \eta(1+\pi)^{\theta}}\right] \frac{P_{t}}{P_{t}(i)} \\
\mu_{t}=\frac{\theta}{\theta-1}\left[\frac{1-\beta^{J}(1+\pi)^{J \theta}}{1-\beta^{J}(1+\pi)^{J(\theta-1)}} \frac{1-\beta(1+\pi)^{\theta-1}}{1-\beta(1+\pi)^{\theta}}\right] \frac{P_{t}}{P_{t}(i)}
\end{gathered}
$$

which present the aggregate mark-up as the product of the firm-level mark-up and price dispersion between aggregate and optimal prices, $P_{t} / P_{t}(i) .{ }^{2}$ Likewise, the definitions of the aggregate price levels in the Calvo and Taylor models determine, respectively, these constant values of price dispersion in steady state

$$
\frac{P}{P(i)}=\left[\frac{1-\eta}{1-\eta(1+\pi)^{\theta-1}}\right]^{\frac{1}{1-\theta}}
$$

\footnotetext{
${ }^{2}$ With positive trend inflation, $\pi>0$, the ratio $P_{t} / P_{t}(i)$ is lower than one in steady state. Furthermore, a higher $\pi$ reduces the value of this price dispersion ratio.
} 


$$
\frac{P}{P(i)}=\left[\frac{1}{J} \frac{1-(1+\pi)^{J(\theta-1)}}{1-(1+\pi)^{\theta-1}}\right]^{\frac{1}{1-\theta}}
$$

Inserting equations (5) and (6) into (3) and (4), respectively, allows us to write down a constant aggregate mark-up, as a function of the Dixit-Stiglitz elasticity parameter $\theta$, the discount factor $\beta$, the level of price rigidity, either $\eta$ or $J$, and the steady-state rate of inflation $\pi$ for both the Calvo and Taylor cases:

$$
\begin{gathered}
\mu=\frac{\theta}{\theta-1} \frac{1-\beta \eta(1+\pi)^{\theta-1}}{1-\beta \eta(1+\pi)^{\theta}}\left[\frac{1-\eta}{1-\eta(1+\pi)^{\theta-1}}\right]^{\frac{1}{1-\theta}} \\
\mu=\frac{\theta}{\theta-1} \frac{1-\beta^{J}(1+\pi)^{J \theta}}{1-\beta^{J}(1+\pi)^{J(\theta-1)}} \frac{1-\beta(1+\pi)^{\theta-1}}{1-\beta(1+\pi)^{\theta}}\left[\frac{1}{J} \frac{1-(1+\pi)^{J(\theta-1)}}{1-(1+\pi)^{\theta-1}}\right]^{\frac{1}{1-\theta}}
\end{gathered}
$$

Equations (7) and (8) provide the impact of trend inflation, $\pi$, on the steady-state aggregate mark-up, $\mu$. There are competing effects on the firm-level mark-up and price dispersion: a positive steady-state inflation rises the firm-level mark-up while it lowers the value of $P / P(i)$ by increasing the distance between optimal and aggregate prices. The higher firm-level mark-up is explained because firms anticipate future inflation and set a higher current optimal price in a forward-looking strategy with price stickiness. Hence, the overall impact of positive trend inflation on the aggregate mark-up depends on the net effect between a higher firm-level mark-up and a lower $P / P(i)$. As documented below, we find that increasing $\pi$ from $0 \%$ reduces the mark-up because the price dispersion effect is stronger than the impact on the firm-level mark-up. In turn, optimal steady-state inflation is positive.

\subsection{Staggered Prices, the Optimal Steady-State Inflation and Welfare}

The optimal steady-state inflation is the one that minimizes $\mu$ in equation (7) for the Calvo model and in equation (8) for the Taylor model. ${ }^{3}$ Assuming that a time period corresponds to one quarter, Table 1 reports the optimal inflation rates for the cases $\rho=[0.005,0.01]$ and $\theta=[4,6,10]$, within both the Calvo and the Taylor specifications and different degrees of price stickiness. Let $Q$ be the average number of quarters without price adjustment so that the cases $\eta=[0.5,0.75,0.875]$ and $J=[2,4,8]$ represent three situations for both models in which prices are optimized semi-annually, annually and biannually. Table 1 compares the optimal annualized inflation to $400 \rho / \theta$. Notably, optimal annualized inflation can be fairly well approximated by the ratio $400 \rho / \theta$, with both sticky-price schemes and for any degree of price stickiness.

To provide additional evidence, Figure 1 displays the annualized per-cent optimal steady-state rate of inflation, in both the Calvo and Taylor specifications, fixing $Q=4$ for a reasonable range of values of $\rho$ and $\theta$. Lines almost overlap, which confirms that optimal inflation is close to $\rho / \theta$ independently

\footnotetext{
${ }^{3}$ As shown in the Supplementary material, no tractable analytical solution for optimal inflation can be derived from the corresponding optimality conditions and numerical methods have been used for its computation.
} 


\begin{tabular}{|c|ccc|ccc|ccc|}
\hline & \multicolumn{3}{|c|}{$\rho=0.005$ and $\theta=4$} & \multicolumn{3}{c|}{$\rho=0.005$ and $\theta=6$} & \multicolumn{3}{c|}{$\rho=0.005$ and $\theta=10$} \\
& Calvo & Taylor & $400 \frac{\rho}{\theta}$ & Calvo & Taylor & $400 \frac{\rho}{\theta}$ & Calvo & Taylor & $400 \frac{\rho}{\theta}$ \\
\hline $\mathrm{Q}=2$ & 0.5015 & 0.4974 & 0.5000 & 0.3333 & 0.3333 & 0.3333 & 0.2012 & 0.2012 & 0.2000 \\
$\mathrm{Q}=4$ & 0.5055 & 0.4974 & 0.5000 & 0.3373 & 0.3333 & 0.3333 & 0.2012 & 0.2012 & 0.2000 \\
$\mathrm{Q}=8$ & 0.5135 & 0.4974 & 0.5000 & 0.3413 & 0.3333 & 0.3333 & 0.2052 & 0.2012 & 0.2000 \\
\hline & \multicolumn{3}{|c}{$\rho=0.01$ and $\theta=4$} & \multicolumn{3}{c|}{$\rho=0.01$ and $\theta=6$} & \multicolumn{2}{c|}{$\rho=0.01$ and $\theta=10$} \\
& Calvo & Taylor & $400 \frac{\rho}{\theta}$ & Calvo & Taylor & $400 \frac{\rho}{\theta}$ & Calvo & Taylor & $400 \frac{\rho}{\theta}$ \\
\hline $\mathrm{Q}=2$ & 1.0060 & 0.9979 & 1.0000 & 0.6736 & 0.6656 & 0.6666 & 0.4054 & 0.3973 & 0.4000 \\
$\mathrm{Q}=4$ & 1.0220 & 0.9979 & 1.0000 & 0.6816 & 0.6656 & 0.6666 & 0.4094 & 0.3973 & 0.4000 \\
$\mathrm{Q}=8$ & 1.0540 & 0.9979 & 1.0000 & 0.7057 & 0.6656 & 0.6666 & 0.4254 & 0.3973 & 0.4000 \\
\hline
\end{tabular}

Table 1: Optimal Annual Rates of Inflation (\%) for Different Sticky-Price Specifications

from the pricing scheme. Let us discuss the economic intuition of this result.

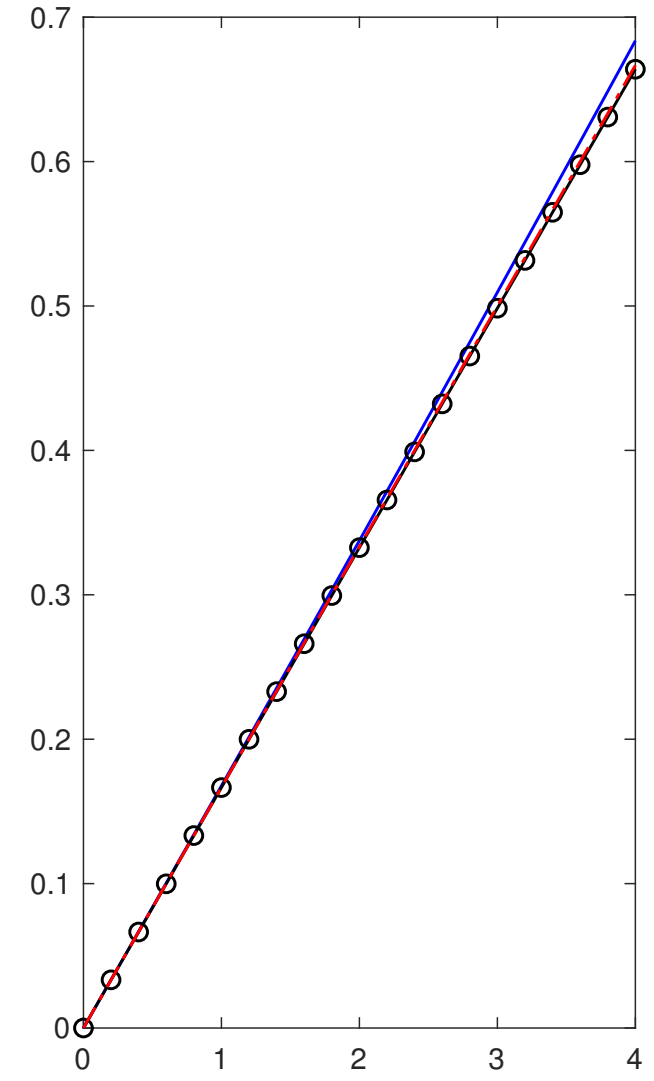

Rate of intertemporal preference (ann. \%), $400 \rho$

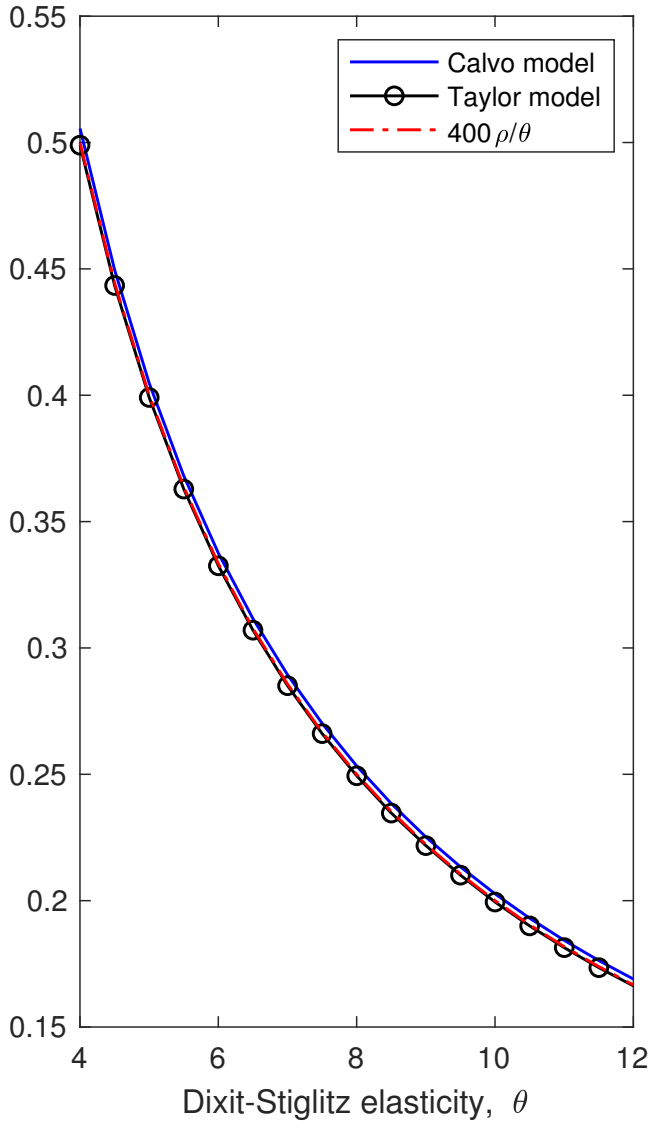

Figure 1: Optimal Rate of Inflation in Steady State (annualized, \%)

An increase in the rate of discount, $\rho$, reduces the present value of future variables. The effects of anticipated future inflation for current price setting are smaller, the optimal price is lower and the firm-level mark-up falls. Since $\rho$ has no influence on price dispersion, $P / P(i)$ does not change, and the aggregate mark-up gets affected only by the reduction of firm-level mark-up. Consequently, a higher 
trend inflation delivers the minimum value of aggregate mark-up.

An increase in the Dixit-Stiglitz elasticity, $\theta$, reduces firm market power and profits. More competition among firms brings less price dispersion and the wedge between optimal and aggregate prices narrows down. This rises the ratio $P / P(i)$ and the decline of the aggregate mark-up due to higher trend inflation is weaker. Subsequently, the optimal rate of inflation is lower with higher Dixit-Stiglitz elasticity. In the limit case, as $\theta$ approaches infinity (perfectly competitive industry), optimal steadystate inflation is null.
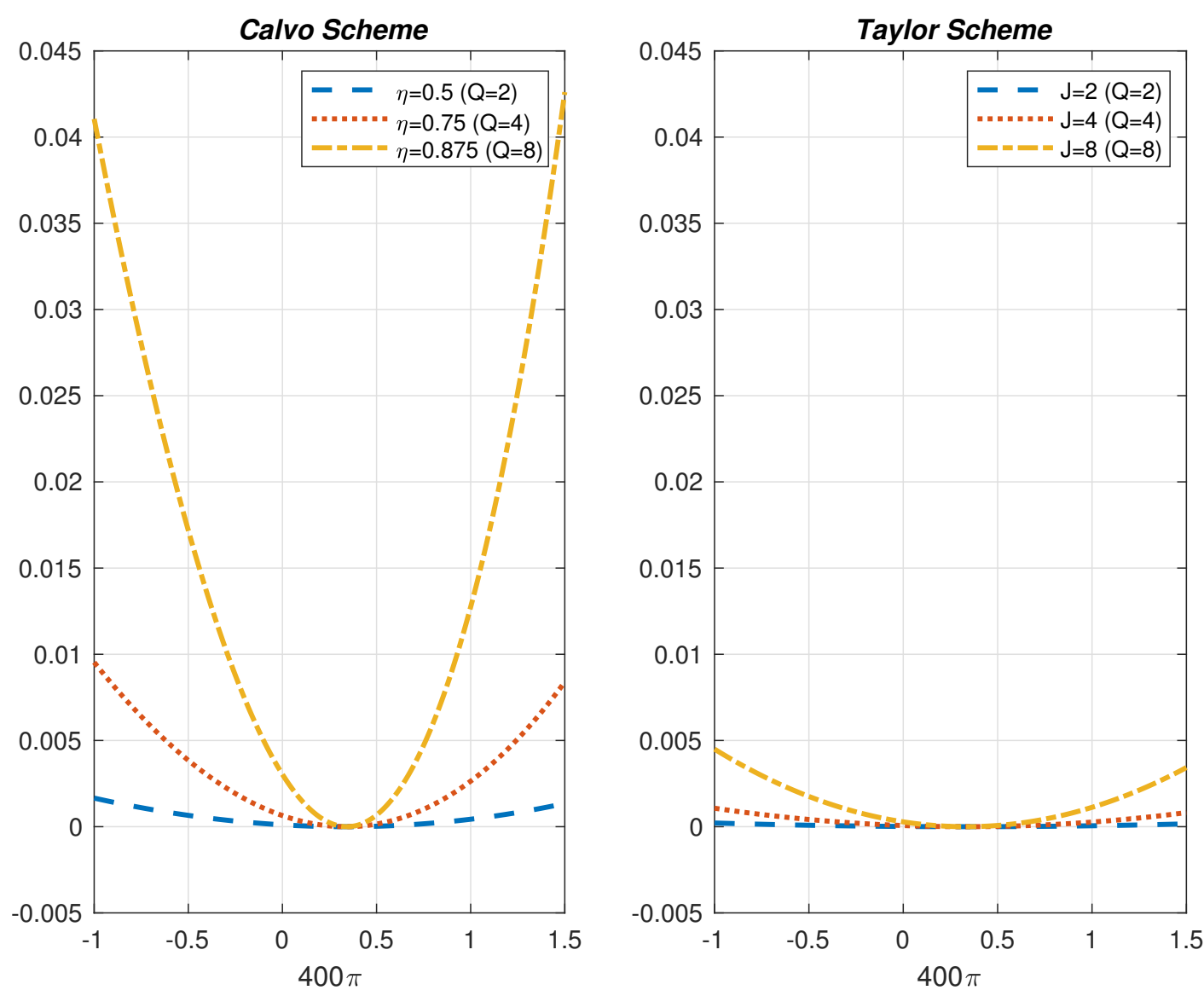

Figure 2: Welfare Cost of Steady-State Inflation (annualized, \%)

The welfare analysis is conducted assuming standard household behavior as described in AguileraBravo and Casares (2019). There is a CRRA utility function with consumption and labor elasticities at 1.25 and 2 , respectively. Households discount future utility at a constant rate $\rho=0.005$, which implies a $2 \%$ annualized rate of discount. The rate of capital depreciation is $2.5 \%$ per quarter and $\alpha=0.36$ in the production function. The Dixit-Stiglitz elasticity is $\theta=6$, which implies a mark-up of prices over the marginal cost approximately equal to $20 \%$. The welfare cost is computed as the percent of output that represents the consumption equivalence when deviating from optimal inflation. 
Figure 2 shows that for all the degrees of price rigidity considered, and with either Calvo or Taylor rigidities, there is a u-shaped pattern representing the welfare cost of steady-state inflation. In other words, household utility is maximized at some positive annualized rate of inflation very close to $400 \rho / \theta=0.33 \%$. Therefore, the degree of price stickiness in either model has very little effect on the optimal rate of inflation in steady state. Nevertheless, Calvo sticky prices entail significantly larger welfare loses than Taylor staggered prices because the mark-up increases much more rapidly when steady-state inflation moves from its optimal value. ${ }^{4}$ The numbers displayed in Figure 2 are rather small due to the narrow interval of inflation rates considered. ${ }^{5}$

Finally, the negative impact of price rigidities on household welfare is also revealed in Figure 2. For a given inflation rate, the longer the average time without adjusting prices, $Q$, the larger the welfare cost. This effect is observed in both Calvo and Taylor schemes.

\section{CONCLUSIONS}

In this paper we have computed the welfare-maximizing rate of inflation in the steady state of a monopolistic competition model under two different sticky-price specifications: Calvo (1983) fixed probability and Taylor (1980) staggered contracts. The maximum welfare is obtained at a steady-state rate of inflation that leads to the minimum mark-up. This optimal rate of inflation is positive due to the eroding effect of higher price dispersion on the aggregate mark-up. We find that the optimal inflation is accurately approximated by the ratio between the rate of discount and the Dixit-Stiglitz elasticity. This result is robust to changes in either the pricing scheme or the level of price stickiness.

Additionally, we report a larger welfare cost of steady-state inflation under Calvo pricing than under Taylor contracts, which increases with price stickiness.

\section{REFERENCES}

Aguilera-Bravo, A., \& Casares, M. (2019). On staggered prices and optimal inflation. Documento de Trabajo 1902, Departamento de Economía, Universidad Pública Navarra.

Calvo, G. A. (1983). Staggered prices in a utility-maximizing framework. Journal of Monetary Economics, 12, 383-398.

Dixit, A. K., \& Stiglitz, J. E. (1977). Monopolistic competition and optimum product diversity. The American Economic Review, 67, 297-308.

\footnotetext{
${ }^{4}$ Kiley (2002) finds the same result.

${ }^{5}$ Nevertheless, the welfare cost rises exponentially with inflation. As an illustrative example, for the case of annual frequency of price adjustment $(Q=4)$, a $10 \%$ annualized inflation results in a welfare cost of $1.2 \%$ of output in Calvo model, and of only $0.05 \%$ of output in Taylor model.
} 
Khan, A., King, R. G., \& Wolman, A. L. (2003). Optimal monetary policy. The Review of Economic Studies, 70, 825-860.

Kiley, M. T. (2002). Partial adjustment and staggered price setting. Journal of Money, Credit and Banking, (pp. 283-298).

King, R. G., \& Wolman, A. L. (1996). Inflation targeting in a st. louis model of the 21st century. Federal Reserve Bank of St. Louis Review, 78, 83-107.

King, R. G., \& Wolman, A. L. (1999). What should the monetary authority do when prices are sticky? In Monetary Policy Rules (pp. 349-404). University of Chicago Press.

Taylor, J. B. (1980). Aggregate dynamics and staggered contracts. Journal of Political Economy, 88, $1-23$. 